\title{
The impact of face shield use on concussions in ice hockey: a multivariate analysis
}

\section{B W Benson, M S Rose, W H Meeuwisse}

See end of article for authors' affiliations .....................

Correspondence to: Dr Benson, c/o Dr Meeuwisse, University of Calgary Sport Medicine Centre, 2500 University Drive NW, Calgary,

Alberta, Canada T2N

1N4;

meeuwiss@ucalgary.ca

Accepted

2 November 2001

\begin{abstract}
Objective: To identify specific risk factors for concussion severity among ice hockey players wearing full face shields compared with half face shields (visors).

Methods: A prospective cohort study was conducted during one varsity hockey season (1997-1998) with 642 male ice hockey players (median age 22 years) from 22 teams participating in the Canadian Inter-University Athletics Union. Half of the teams wore full face shields, and half wore half shields (visors) for every practice and game throughout the season. Team therapists and doctors recorded on structured forms daily injury, participation, and information on face shield use for each athlete. The main outcome measure was any traumatic brain injury requiring assessment or treatment by a team therapist or doctor, categorised by time lost from subsequent participation and compared by type of face shield worn.

Results: Players who wore half face shields missed significantly more practices and games per concussion (2.4 times) than players who wore full face shields $(4.07$ sessions $195 \%$ confidence interval $(\mathrm{Cl})$ 3.48 to 4.74$)$ v 1.71 sessions $(95 \% \mathrm{Cl} 1.32$ to 2.18 ) respectively). Significantly more playing time was lost by players wearing half shields during practices and games, and did not depend on whether the athletes were forwards or defence, rookies or veterans, or whether the concussions were new or recurrent. In addition, players who wore half face shields and no mouthguards at the time of concussion missed significantly more playing time $(5.57$ sessions per concussion; $95 \% \mathrm{Cl} 4.40$ to 6.95 ) than players who wore half shields and mouthguards (2.76 sessions per concussion; $95 \% \mathrm{Cl} 2.14$ to 3.55 ). Players who wore full face shields and mouthguards at the time of concussion lost no playing time compared with 1.80 sessions lost per concussion $(95 \% \mathrm{Cl} 1.38$ to 2.34$)$ for players wearing full face shields and no mouthguards.

Conclusions: The use of a full face shield compared with half face shield by intercollegiate ice hockey players significantly reduced the playing time lost because of concussion, suggesting that concussion severity may be reduced by the use of a full face shield.
\end{abstract}

$\mathrm{P}$ ublic and professional concern about the number and severity of concussions occurring in ice hockey is increasing. These injuries are one of the most dangerous types sustained in sport and therefore prevention is of paramount importance. ${ }^{1}$ Hockey associations world wide have tried to reduce the incidence of head injuries through strict rule enforcement and by making the use of helmets and face shields mandatory. ${ }^{2}{ }^{3}$ However, despite such efforts, concussions remain one of the most common types of injury sustained in this sport. ${ }^{4-10}$

Concussion has been defined as a trauma induced alteration in mental status that may or may not involve loss of consciousness. ${ }^{112}$ The terms concussion and traumatic brain injury are used interchangeably in this paper, as is consistent with the medical literature. ${ }^{13}$ It has been estimated that $1.5-2$ million new cases of traumatic brain injury occur annually in the United States, with more than 300000 occurring in sport. ${ }^{14}$ Although alarming, this figure may be an underestimation because the side effects associated with milder forms of concussion are generally transient and therefore may go unnoticed by doctors, trainers, therapists, coaches, and parents. Furthermore, many sports participants themselves are unaware that repeated minor head injuries may be unresponsive to medical treatment and cause cumulative brain damage. ${ }^{121516}$ Therefore athletes may be reluctant to report such injuries to trainers or medical personnel.

Sport related concussions are a distinct clinical subset of traumatic brain injury because they are often witnessed and not usually associated with other injury. More than $90 \%$ of these injuries are of mild severity characterised by transient confusion, brief amnesia, and no loss of consciousness. ${ }^{17}$ Thus it is possible for an athlete to be concussed and still continue to play. Also, management decisions are easily influenced by an athlete's desire to return to competition and a coach's will to win. ${ }^{18}$ Although some traumatic brain injuries are more severe than others, none are trivial, and each has the potential to be lethal. ${ }^{19}$

Although extensive research of traumatic brain injury has provided some understanding of the biomechanics and pathophysiology of injury, specific risk factors for sport related concussions are poorly delineated and rarely studied, leaving large gaps in the knowledge of appropriate prevention strategies. ${ }^{120}$ Until recently, there was speculation that the added mass and area of a helmet and full face shield may increase the rotational acceleration of a player's head following impact, producing greater neuronal shearing forces and increased concussion severity. ${ }^{21}$ However, one of our studies showed that concussion severity may actually be greater for athletes wearing half shields than for those wearing full face shields because these players missed significantly more practices and games due to concussion. ${ }^{5}$ To our knowledge, no research has been conducted to identify risk factors that may increase concussion severity associated with the use of different types of facial protection.

The purpose of this study was to identify specific risk factors associated with increased concussion severity among ice hockey players wearing full face shields compared with half face shields. 


\section{METHODS}

A more detailed description of the methods has been previously published. ${ }^{5}$ This prospective cohort study was conducted during the 1997-1998 Canadian Inter-University Athletics Union (CIAU) hockey season. The CIAU is a national league consisting of four divisions with identical officiating and player eligibility rules except that each division may mandate the use of protective equipment. The Ontario Universities Athletic Association (OUAA) requires all athletes under its jurisdiction to wear full face shields for every practice and game throughout the varsity season. In contrast, the Canada West Universities Athletic Association (CWUAA) and Atlantic Universities Athletic Association (AUAA) mandate all athletes to wear at the very least half shields (visors) for all practices and games. For this study, two cohorts were defined by their exposure to mandated facial protection.

\section{Subjects and data collection}

The study population included 642 male ice hockey players from 11 CIAU teams competing in the OUAA, seven teams in the CWUAA, and four teams in the AUAA. Thus athletes from the 11 OUAA and 11 CWUAA/AUAA teams formed the cohorts wearing full face shields and half face shields respectively.

Approved by the bioethics committee of the University of Calgary, this study required team therapists to obtain informed verbal consent from all players before participation. Previous injury status was documented for each CWUAA player using a standardised medical form during a mandatory preseason medical examination with the team doctor. Because team doctors of institutions participating in the OUAA and AUAA did not uniformly use standardised forms, athletes competing in these divisions completed an injury history questionnaire with their team therapist during a preseason meeting. The injury information recorded on these forms served as a baseline for the 1997-1998 hockey season. From the first organised practice of the season, team therapists recorded the level of individual participation (full, partial, or none) and the type of face shield worn for every practice and game throughout the season. If a player sustained an injury that met the reportable injury definition, team therapists, doctors, or both were required to complete an injury report form. ${ }^{22}$ The athlete participation forms were designed so that it could be determined (on a daily basis) which injury resulted in time loss from competition if more than one injury was sustained during a single event. Thus the analysis of injury related time loss in this paper reflects time loss because of concussion. A subjective assessment of whether an injury was the result of an illegal play was included on the injury report form so that a descriptive comparison could be made with respect to style of play between facial protection divisions. The completed forms were sent to the Canadian Intercollegiate Sport Injury Registry (at Calgary) (CISIR) where they were checked, coded, and entered into a database using a dual entry system to minimise data entry errors. ${ }^{22}$

\section{Outcome variables and statistical analysis}

The injury definition or main outcome variable measured in this study was "any traumatic brain injury that required assessment or treatment by a team therapist or doctor regardless of playing time lost." Reportable injuries were then categorised by the amount of time lost from subsequent participation to give an indication of concussion severity.

The independent variable of interest was a full face shield $v$ half face shield. Individual athlete participation (exposure), defined as one player participating in one practice or game who was exposed to the possibility of injury, was measured to determine the exact amount of time under the different exposure conditions that each player was at risk of injury. Athlete exposures were calculated by weighting a full session of
Table 1 Descriptive characteristics of the study population

\begin{tabular}{lll}
\hline Athlete characteristics & Full shield & Half shield \\
\hline Number of athletes & 319 & 323 \\
Number of athletes injured & 195 & 204 \\
Median age & 22 & 22 \\
Previous injury (\%) & 87.9 & 95.1 \\
Previous concussion (\%) & 55.6 & 55.3 \\
Rookies (\%) & 41.9 & 39.5 \\
Veterans (\%) & 58.1 & 60.5 \\
\hline
\end{tabular}

participation as 1 , a partially missed session as 0.5 , and a completely missed session as 0 . For example, 25 athletes fully participating in 10 games would yield 250 game athlete exposures. Information on goaltender exposure and injury was not included in the analyses so that a true comparison could be made between players wearing full face shields and those wearing half face shields. In addition, several potential risk factors for concussion severity were assessed, including injury setting (game $v$ practice), position (forward $v$ defence), previous concussion status (new $v$ recurrent), and experience level (rookie $v$ veteran). Concussion severity associated with mouthguard use (both commercial and custom fitted by dentists) was assessed independently for each cohort. An analytical comparison was not conducted because individual exposure information on mouthguard use was not collected by the therapists, and athletes from the half shield cohort had division rules in place that mandated the use of mouthguards, while no such rules were in effect for the cohort wearing full face shields.

The sample size of this study (642) was chosen from a previous investigation. ${ }^{5}$ Based on the finding that concussions accounted for about $16 \%$ of the total reported injuries sustained by players wearing full face shields ${ }^{5}$ and using a two sided test $(\alpha=0.05, \beta=0.20)$, it was estimated that 258 subjects in each group $(n=516)$ would be required in this study to achieve $80 \%$ power to detect a relative risk of 2.0 or more between the two study groups. StataQuest 4 (Belmont, California, USA) was used to calculate Poisson confidence intervals for the playing time lost per concussion.

\section{RESULTS}

\section{Athlete characteristics}

All 642 varsity athletes from the 22 participating teams consented to have data collected and sent to the CISIR. Athlete exposure (participation) information was $100 \%$ complete throughout the 1997-1998 hockey season, and all but one injury report form involving time loss from participation was sent to the CISIR (99.9\% completion rate). It was not possible to determine the completion rate for injuries that did not result in time lost from participation.

Table 1 provides a descriptive comparison of the two study groups. Of note, $11.9 \%$ and $9 \%$ of athletes competing in the full and half shield divisions respectively did not have medical forms or injury history questionnaires returned to the central registry. These players participated for only a minimum duration of time on a varsity team or joined a team later in the season.

\section{Concussion incidence}

Forty one concussions were sustained by players wearing half face shields during the 1997-1998 season compared with 38 by players wearing full face shields at the time of injury. The incidence of concussion in Canadian intercollegiate ice hockey was 1.55 per 1000 athlete exposures. Based on the absolute number of concussions sustained by players from both cohorts during the 1997-1998 season $(\mathrm{n}=79$ ), we can expect to see an 
Table 2 Mechanism of concussion for the two study groups by absolute number of injuries and subsequent playing time lost from games and practices

\begin{tabular}{|c|c|c|c|c|c|c|}
\hline \multirow[b]{2}{*}{ Mechanism of concussion } & \multicolumn{3}{|c|}{ Half face shield } & \multicolumn{3}{|c|}{ Full face shield } \\
\hline & $\begin{array}{l}\text { No of } \\
\text { injuries }\end{array}$ & Time loss* & $\begin{array}{l}\text { Time loss } \\
\text { per injury }\end{array}$ & $\begin{array}{l}\text { No of } \\
\text { injuries }\end{array}$ & Time loss* & $\begin{array}{l}\text { Time loss } \\
\text { per injury }\end{array}$ \\
\hline Player contact (open ice) & 20 & 97.0 & 4.85 & 11 & 15.5 & 1.41 \\
\hline Boards, glass, or net contact & 14 & 61.5 & 4.39 & 17 & 23.0 & 1.35 \\
\hline Skate contact & 1 & 5.5 & 5.50 & 0 & 0.0 & 0.0 \\
\hline Stick contact & 2 & 1.0 & 0.50 & 5 & 18.0 & 3.60 \\
\hline Ice contact & 2 & 1.5 & 0.75 & 3 & 5.5 & 1.83 \\
\hline Puck contact & 0 & 0.0 & 0.0 & 1 & 2.5 & 2.50 \\
\hline Unknown & 2 & 0.0 & 0.0 & 1 & 0.0 & 0.0 \\
\hline Total & 41 & 166.5 & 15.99 & 38 & 64.5 & 10.69 \\
\hline
\end{tabular}

average of three to four concussions per team during any given season. The overall risk of sustaining a concussion was not significantly different for players wearing half shields compared with those who wore full facial protection at the time of injury $(\mathrm{p}=0.90)$.

Most concussions sustained by players in both study groups occurred during regular season play (full shield, 27; half shield, 26), followed by exhibition season (full shield, 7; half shield, 6), and playoffs (full shield, 4; half shield, 2). All 38 concussions sustained by players competing in the full shield division occurred during organised games ( 13 home games, 21 away games), compared with 34 of the 41 concussions sustained by athletes competing in the half shield divisions ( 9 home games, 24 away games). Most of the game concussions occurred in the second period (full shield, 16; half shield, 14), followed by the third (full shield, 10; half shield, 11) and first periods (full shield, 8; half shield, 8). For players in the full shield division, the period of injury was not reported on three injury report forms, and the game setting was not reported on four forms. In the half shield divisions, game setting and period of injury were not recorded on one injury report form. A $\chi^{2}$ analysis of the data showed a non-significant difference between the two groups for season of injury $(p=0.76)$, period of concussion $(p=0.92)$, and game setting-that is, home $v$ away $(\mathrm{p}=0.34)$.

\section{Reported concussion factors}

Table 2 highlights the mechanism of concussions sustained by players from the two study groups and the subsequent playing time lost from games and practices. Direct player contact was the predominant mechanism of injury for athletes wearing half shields resulting in an average of 4.85 games and practices lost per concussion. In comparison, contact with the boards, plexiglas, or net following a body check caused most concussions among athletes wearing full face shields resulting in an average of 1.35 sessions lost per concussion.

Elbowing and checking from behind were the top two reported types of illegal play causing concussion for athletes competing in the half shield divisions. In comparison, checking from behind was the most common type of reported illegal play causing concussion in the full face shield division, followed by cross checking and elbowing, which were tied for the next most common type of illegal play resulting in concussion.

Team therapists reported that $47.1 \%$ of game concussions sustained by players competing in the half shield divisions were caused by an illegal play, compared with $50 \%$ for players competing in the full face shield division.

\section{Concussion severity}

Table 3 highlights the severity of concussions sustained by players from the two study groups based on the amount of time lost from competition. Twenty five athletes who
Table 3 Severity of concussions sustained by players from the two study groups, as measured in time lost from practices and games (sessions)

\begin{tabular}{lll}
\hline Concussion severity & Half shield & Full shield \\
\hline Mild (<1 session) & 17 & 25 \\
Moderate (1-7 sessions) & 17 & 12 \\
Severe ( $>7$ sessions) & 7 & 1 \\
Total & 41 & 38 \\
\hline
\end{tabular}

sustained concussions from the full shield division missed less than one full game or practice (mild severity) because of a concussion compared with 17 athletes from the half shield divisions. Twelve athletes wearing full face shields at the time of injury missed between one and seven sessions (moderate severity) compared with 17 players who wore half face shields at the time of concussion. Only one player wearing a full face shield missed more than seven sessions (severe concussion) compared with seven players who wore half face shields at the time of injury. In addition, five players in the half shield cohort who lost consciousness were immediately transferred to the hospital, compared with three players (one of whom lost consciousness) in the full face shield cohort.

Table 4 highlights stratum specific information on playing time lost per concussion for the two study groups. Overall, players who wore half face shields at the time of injury missed significantly more practices and games per injury (4.07 sessions per concussion; $95 \%$ confidence interval (CI), 3.48 to 4.74) than players who wore full face shields at the time of injury ( 1.71 sessions per concussion; $95 \%$ CI 1.32 to 2.18 ). The playing time lost per concussion sustained during a game was significantly greater for players who wore half face shields (3.29 sessions lost per concussion; 95\% CI 2.71 to 3.96) compared with full face shields ( 1.70 sessions lost per concussion; $95 \%$ CI 1.32 to 2.18). No athletes sustained concussions during practices while wearing a full face shield compared with seven athletes ( 54.5 sessions lost) who wore half face shields at the time of concussion.

The playing time lost per concussion for players wearing half shields with no previous concussion history was significantly greater than for players who wore full face shields with no previous concussion history (half shield, 2.09 sessions lost per concussion, $95 \%$ CI 1.48 to 2.93; full shield, 1.0 session lost per concussion, $95 \%$ CI 0.57 to 1.62 ). In addition, players who sustained a recurrent concussion while wearing a half face shield missed at least 1.41 times more games and practices per concussion than players who sustained a recurrent concussion while wearing a full face shield at the time of injury. Because three athletes who wore half shields at the time of concussion ( 59 sessions lost) did not 
Table 4 Playing time lost per concussion, stratified by injury setting, injury status, position, and experience level

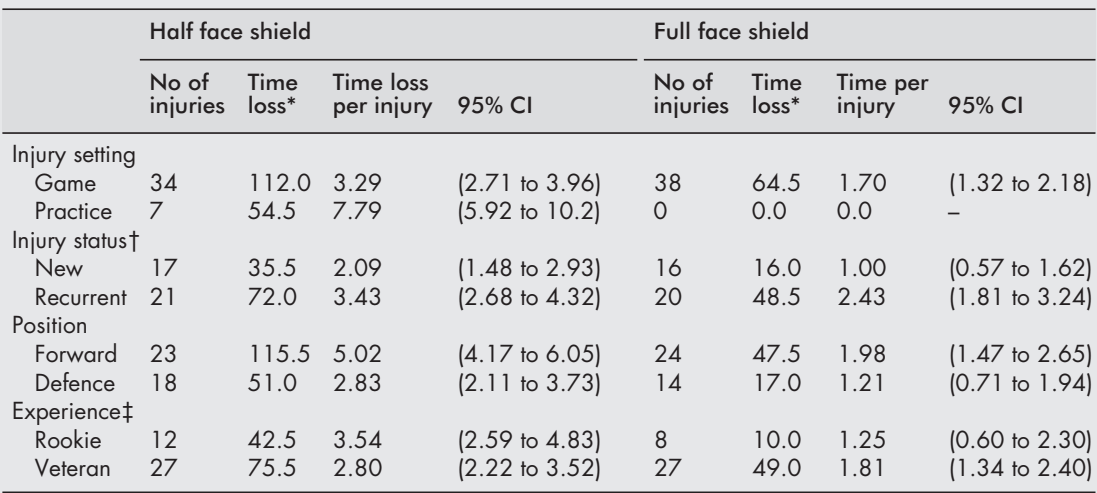

*Playing time lost in sessions, where 1 session = 1 game or practice; †unknown: Half shield (three concussions, 59.0 time loss sessions), full shield (two concussions); funknown: Half shield (two concussions, 48.5 time loss sessions), full shield (three concussions, 5.5 time loss sessions).

have medical forms returned to the CISIR, it was not possible to determine whether these athletes sustained a new or recurrent concussion. Thus the stratum specific rates of time loss for concussion for players wearing half shields were underestimated.

Both forwards and defence who were concussed while wearing a half shield missed significantly more practices and games per concussion than those who wore full face shields at the time of injury (forwards, 2.54 times more sessions lost per concussion; defence, 2.34 times more sessions lost per concussion). In addition, rookies and veterans who wore half shields at the time of injury missed at least 2.83 times and 1.55 times more sessions per concussion respectively than those who wore full face shields at the time of concussion. Two athletes who wore half shields at the time of concussion (48.5 sessions lost) did not have medical forms returned to the CISIR, and therefore the time loss rates for experience level for players wearing half shields were underestimated.

Twenty three players who wore mouthguards and half face shields at the time of concussion missed 2.76 sessions per concussion (95\% CI 2.14 to 3.55 ) compared with 5.57 sessions per concussion (95\% CI 4.40 to 6.95) among 14 players wearing half face shields and no mouthguards. Two players who wore full face shields and mouthguards at the time of concussion did not miss any playing time (0 sessions per concussion; one sided $97.5 \%$ CI 0 to 1.84 ) compared with 1.80 sessions per concussion among 32 players wearing full face shields and no mouthguards ( $95 \%$ CI 1.38 to 2.34 ). Of note, it was not known whether a mouthguard was worn at the time of concussion for four players competing in the half shield divisions (25.0 sessions lost) and four players competing in the full shield division ( 7.0 sessions lost).

\section{DISCUSSION}

Sport related concussion is of major public health significance. ${ }^{1}$ These injuries are the predominant reason for hospital admission after trauma and, although rare, catastrophic outcomes have been reported in the literature. ${ }^{23}{ }^{24}$ In addition, concussions often occur in sporting competitions where no medical personnel are readily available to treat them. This puts athletes at increased risk because complications may develop that require neurosurgical care, and early management is essential for limiting catastrophic outcome. ${ }^{121618}$ Furthermore there is evidence to suggest that cumulative brain damage is associated with repeated concussions; many athletes who sustain these injuries have persistent symptoms or neuropsychological deficits that result in social dysfunction, lost productivity, and excessive healthcare costs. ${ }^{1518}$
Several strategies for concussion risk management have been proposed to date, including use of mouthguards, conditioning of neck musculature, use of properly fitted and maintained helmets, strict enforcement of rules, stiffer penalties for illegal play, enhanced coaching techniques, and improved medical care, including on field recognition and treatment. ${ }^{2123}$ None of these strategies, however, has been uniformly implemented by hockey associations, primarily because of a lack of scientific evidence to support their effectiveness in reducing the incidence of concussion. Recurrent problems that surface in the literature with respect to the study of sport related concussion include: (a) reporting and memory biases associated with retrospective designs; $(b)$ lack of uniformity in the definition of injury; $(c)$ lack of data on the population at risk of injury; and $(d)$ unknown validity of the recording mechanisms. ${ }^{25}$

This study is unique in that it prospectively evaluated risk factors for concussion severity in a natural experimental setting using two cohorts who differed only in their exposure to face shield use. Players from the two study groups competed during the same time periods and were similar with respect to age, experience level, previous injury status, and skill level. In addition, the data were collected using a previously validated system of injury surveillance ${ }^{22}$ and were nearly $100 \%$ complete.

Misclassification or information bias results from systematic differences in the way data on exposure or outcome are obtained from the various study groups. ${ }^{26}$ There was potential for non-differential misclassification injury reporting bias in this study as there was no method of verifying the completeness of reporting for injuries resulting in no time lost from participation. However, it was assumed that all concussions were reported because the data were gathered by athletic therapists and team doctors, who were front line healthcare professionals during every practice and game and had the highest likelihood of observing a concussion as it occurred. Also the increased national and international attention of sport related concussions would have heightened players' awareness of the risks and increased their likelihood of reporting these injuries to medical personnel. In addition, it was possible that team therapists and doctors differed in their thresholds to allow a player to return to competition after a concussion. However, the probability that the 11 OUAA team therapists and doctors were systematically more "conservative" in managing concussions than the 11 CWUAA/AUAA therapists and doctors was highly unlikely. Also there was no clustering of concussions on any one particular team within either cohort, and the concussion playing time lost within the half shield cohort did not differ significantly between the 
CWUAA and AUAA divisions. To our knowledge the CWUAA, OUAA, and AUAA team therapists and doctors were not uniformly obligated to use one specific set of concussion guidelines to manage their athletes.

We found evidence to suggest that use of half face shields compared with full face shields was a specific risk factor for increased concussion severity as measured by time lost from competition. Players who wore half face shields at the time of concussion missed significantly more practices and games per concussion than players who wore full face shields regardless of injury setting, previous concussion status, position, or experience level.

Several other findings warrant comment. Firstly, evidence was provided in this study to suggest that mouthguard use reduced concussion severity. The two players from the full shield cohort who sustained a concussion while wearing a mouthguard did not miss any subsequent playing time because of their concussions. In addition, the 14 players from the half face shield cohort who did not wear mouthguards at the time of concussion missed more than twice as many practices and games per injury than the 23 players who sustained concussions while wearing a half shield and mouthguard at the time of injury. Amateur high school and college hockey (NCAA) in the United States as well as several Canadian hockey leagues currently have playing rules that mandate the use of mouthguards. However, coaches are primarily responsible for monitoring compliance, and it has been shown that only about one third of all players comply with this rule because of lack of comfort and ventilation and speech difficulties. ${ }^{27}$ When worn properly, mouthguards have been reported to decrease the risk of jaw fractures and reduce dental and concussion injury rates by $70 \%$ and $75 \%$ respectively. ${ }^{28}$ Modification of commercial mouthguards by making them smaller, however, has been shown to dramatically diminish this protective effect. ${ }^{27}$ Further research is needed to determine players' risk of sustaining a concussion associated with mouthguard use.

Secondly, no concussions were sustained throughout the entire 1997-1998 season by players who wore full face shields during practices. In contrast, seven players from the half shield cohort sustained concussions during practices, which resulted in an average of 7.79 sessions lost per concussion. This finding suggests that use of full face shields during practices protected against concussion. A possible explanation for this finding may be that no referees are present during practices to force players to wear their helmet and half shield units properly. During games, a penalty is given to any player who does not fasten his chinstrap or who does not wear his helmet and half shield unit so that the visor extends down to the tip of his nose. Therefore athletes who wear half shields during practices are given the freedom to wear their helmets in a manner such that the visors are raised above the level of their eyes in order to get a clearer view of the play. If the helmet is tipped back in this position, the protective effect of the padding is minimised, predisposing the wearer to increased concussion severity. ${ }^{5}$ In addition, the helmet and half shield unit of players who do not fasten their chinstraps during practices may shift from its intended position during impact with an opposing player, thereby decreasing its protective effect. In contrast, the chin piece of the full face shield helps to hold the helmet in place during impact, thereby maintaining maximum protection from concussion. ${ }^{5}$ Another possible explanation for the overall observed reduction in concussion severity among players wearing full face shields is that the full shield helps to disperse and absorb impact forces to a greater extent than would be transmitted to the brain from a direct blow to an exposed jaw.

Thirdly, direct player contact and contact with the boards, plexiglas, or net after a body check were the top two mechanisms of concussion for players wearing both full face shields and half shields. These mechanisms are considered by

\section{Take home message}

It would appear that the lowest risk of concussion in ice hockey would be to a player wearing a full face shield possibly with a mouthguard.

many to be an inherent part of the game. However, referees must be vigilant for checking from behind, elbowing, cross checking, and high sticking, all of which were shown to be common types of illegal play causing concussion in this study. Furthermore, referees must not alter the way in which they "police" the game with the evolution of improved protective equipment, especially in leagues that mandate full face shield use where the consequences of illegal play-for example, facial lacerations, dental fractures, etc-are not as evident. ${ }^{5}$

In reality, it is impossible to avoid all risk in sport. The probability that one piece of protective equipment can prevent $100 \%$ of the injuries to its intended anatomic region is low. This is especially true in ice hockey, which has many inherent features that predispose players to injury, including high acceleration-deceleration, rapidly changing directions, shooting, body checking, and a low friction ice surface. These characteristics result in frequent collisions between players and forceful impacts with the side boards, goal posts, pucks, and hockey sticks. The goal then is to avoid unnecessary foreseeable risk and try to control that which is understood to be inherent to the sport. ${ }^{29}$

Finally, these findings are based on data from adult collegiate hockey players and may not be generalisable to high school and younger skeletally immature players.

In this study the use of full face shields was associated with significantly less loss of playing time because of concussion as compared with half face shields. This finding supports the suggestion that half shield use may be a specific risk factor for increased concussion severity. ${ }^{5}$ Athletes must be educated about the risks of concussion and encouraged to wear full face shields and mouthguards in practices and games to reduce the risk of long term disability associated with concussion.

\section{ACKNOWLEDGEMENTS}

Funding for this project was provided by the Canadian Hockey Association and Olympic Oval Research Fund, Calgary, Alberta, Canada.

\section{Authors' affiliations}

B W Benson, M S Rose, Faculty of Medicine, University of Calgary, Calgary, Alberta, Canada

W H Meeuwisse, University of Calgary Sport Medicine Centre, Faculty of Kinesiology, University of Calgary, Calgary, Alberta, Canada

\section{REFERENCES}

1 NIH consensus development panel on rehabilitation of persons with traumatic brain injury. Rehabilitation of persons with traumatic brain injury. JAMA 1999;282:974-83.

2 Dixon J. The Canadian standards association and the evolution of head and face protection in Canadian hockey. In: Castaldi CR, Hoerner EF, eds. Safety in ice hockey. Philadelphia, PA: American Society for Testing and Materials, 1989:207-19.

3 Parayre R. The effect of rules and officiating on the occurrence and prevention of injuries. In: Castaldi CR, Hoerner EF, eds. Safety in ice hockey. Philadelphia, PA: American Society for Testing and Materials, 1989:37-43.

4 Bishop P, Norman R, Pierrynowski M, et al. The ice hockey helmet: how effective is it? Physician and Sports Medicine 1979;7:97-106.

5 Benson BW, Mohtadi NGH, Rose MS, et al. Head and neck injuries among ice hockey players wearing full face shields vs half face shields. JAMA 1999;282:2328-32.

6 Brust JD, Leonard BJ, Pheley A, et al. Children's ice hockey injuries. American Journal of Diseases in Children 1992;146:741-7.

7 Goodwin-Gerberich S, Finke R, Madden M, et al. An epidemiologic study of high school ice hockey injuries. Childs Nervous System 1987;3:59-64. 
8 Pelletier R, Montelpare W, Stark R. Intercollegiate ice hockey injuries: a case for uniform definitions and reports. Am J Sports Med 1993;21:78-82

9 Rampton J, Leach T, Therrien SA, et al. Head, neck, and facial injuries in ice hockey: the effect of protective equipment. Clin J Sport Med 1997:7:162-7.

10 Jorgensen U, Schmidt-Olsen S. The epidemiology of ice hockey injuries. BrJ Sports Med 1986;20:7-9.

11 Kelly JP, Rosenberg JH. Diagnosis and management of concussion in sports. Neurology 1997:48:575-80.

12 Report of the Quality Standards Subcommittee, American Academy of Neurology. Practice parameter: the management of concussion in sports (summary statement). Neurology 1997;48:581-5.

13 Kelly JP. Traumatic brain injury and concussion in sports. JAMA 1999:282:989-91.

14 Sports-related recurrent brain injuries - United States. MMWR Morb Mortal Wkly Rep 1997;46:224-7.

15 Matser EJ, Kessels AG, Lezak MD, et al. Neuropsychological impairment in amateur soccer players. JAMA 1999;282:971-3.

16 Tellier A, Della Malva LC, Winn AC, et al. Mild head injury: a misnomer. Brain Injury 1999;13:463-75.

17 Cantu RC. Reflections on head injuries in sport and the concussion controversy (editorial). Clin J Sport Med 1997;7:83-4.

18 Vollmer DG, Dacey RG Jr. The management of mild and moderate head injuries. Neurosurg Clin N Am 1991;2:437-55.

19 Cantu R. Minor head injuries in sports. Adolescent Medicine. State of the Art Review 1991;2:141-54.

20 Walker AE. The physiological basis of concussion: 50 years later. $J$ Neurosurg 1994:81:493-4.

21 Brukner P. Sports medicine: concussion. Aust Fam Physician 1996;25:1445-8.

22 Meeuwisse WH, Love EJ. Development, implementation and validation of the Canadian intercollegiate sport injury registry. Clin J Sport Med 1998;8:164-77.

23 Cantu RC. Cerebral concussion in sport. Management and prevention. Sports Med 1992;14:64-74.

24 Thurman D, Guerrero J. Trends in hospitalization associated with traumatic brain injury. JAMA 1999;282:954-7.

25 Honey C. Brain injury in ice hockey. Clin J Sport Med 1998;8:43-6.

26 Hennekens $\mathrm{CH}$, Buring JE. Epidemiology in medicine. Boston: Little, Brown and Company, 1987

27 Castaldi C. The sports mouthguard: its use and misuse in ice hockey. In Castaldi CR, Bishop PJ, Hoerner, EF, eds. Safety in ice hockey. Philadelphia, PA: American Society for Testing and Materials, 1993:164-74.

28 Mastrangelo F. Eye and face injuries in high school hockey: cutting down the risks. In: Castaldi CR, Hoerner EF, eds. Safety in ice hockey Philadelphia, PA: American Society for Testing and Materials, 1989:52-4.

29 Clarke J. Cornerstones for future directions in head/neck injury prevention in sports. In: Hoerner EF, ed. Head and neck injuries in sports. Philadelphia: American Society for Testing and Materials, 1994:3-9.

\section{COMMENTARY}

Concussion is a significant problem in ice hockey at all levels, from youth to professional. It is critical that research be carried out to look at ways to reduce the risk and severity of this potentially devastating injury. It is well accepted that full facial protection has virtually eliminated facial injury in hockey. ${ }^{1}$ A popular "myth" was that wearing increased facial protection may actually increase injury incidence and severity, because of the increased weight of the facial protection, inability to see as well, and more rough play when players feel more protected. The authors' previous study showed clearly that this was not the case. ${ }^{2}$ This study looks further into one of the first study's observations, and shows that concussion severity is also reduced by full facial protection. It also suggests that style of play and rule enforcement are important factors in reducing concussion risk. Mouthguards are a more controversial issue; while there appeared to be a protective effect from mouthguards in terms of time lost because of concussion, the numbers in the study were small. More research is needed to determine the effect of mouth guards in reducing concussion risk and severity, not only in hockey, but in all sports.

J Kissick

Palladium Sport Medicine Centre, 1000 Palladium Drive, Kanata, Ontario K2V 1A4, Canada jkissick@cyberus.ca

\section{REFERENCES}

1 Canadian Academy of Sport Medicine Sport Safety Committee. Position statement: use of full facial protection in ice hockey. Clin J Sport Med 2000;10:212-13

2 Benson BW, Mohtadi NG, Rose MS, et al. Head and neck injuries among ice hockey players wearing full face shields vs half face shields. JAMA 1999;282:2328-32.

\section{COMMENTARY}

This study gives the ice hockey community an immediate solution to the severity of concussion in players beyond strict enforcement of the rules and player to player respect. Although the incidence of concussion will only decrease if the heavy hitting and illegal hitting is decreased, the full shield and the mouthguard offer the opportunity to reduce the severity of concussion which may decrease the cumulative effect of repeated concussions.

A tag on to this study, the effect of wearing a mouthguard on the severity of concussion, is significant because it supports the use of mouthguards to reduce concussion injury. In the early 1960s, when the mouthguard was made mandatory in American football, the medical staff at Notre Dame reported a $50 \%$ reduction in concussion in the first season. Players should be fitted for mouthguards and be required to use them during practice and competition, and officials should make the penalty call when the mouthguard is not properly used.

W O Roberts,

Department of Family Practice and Community Health, MinnHealth Family Physicians, 4786 Banning Avenue, White Bear Lake, MN 55110 , USA rober037@umn.edu 